\title{
PENGARUH LAYANAN BIMBINGAN KELOMPOK DENGAN TEKNIK PERMAINAN SIMULASI TERHADAP KEPERCAYAAN DIRI
}

\author{
Berta Desriana \\ Program Studi Bimbingan dan Konseling, Universitas PGRI Semarang, Indonesia \\ e-mail: berta.desriana96@gmail.com
}

\begin{abstract}
ABSTRAK
Penelitian ini dilatarbelakangi oleh permasalahan siswa 1) belum berani untuk mengemukakan pendapat didepan kelas, merasakan takut dan cemas dalam menghadapi penolakan, 2) belum bisa menyesuaikan diri dengan teman kelasnya, 3) masih terdapat siswa yang memandang rendah kemampuan diri sendiri yang mereka miliki, dan belum bisa menerima keadaan diri sendiri. Penelitian ini bertujuan untuk mengetahui ada tidaknya pengaruh layanan bimbingan kelompok dengan teknik permainan simulasi terhadap kepercayaan diri siswa kelas X MA Futuhiyyah 2 Mranggen. Jenis penelitian ini adalah penelitian kuantitatif desain true experimental design dengan model pre-test post-test control group design. Populasi dalam penelitian ini adalah 210 siswa. Sampel dalam penelitian yaitu 30 siswa, diambil dengan menggunakan teknik cluster random sampling. Dapat dilihat berdasarkan hasil pre-test dan post-test. Rata-rata pre-test yaitu 73,47 , sedangkan rata-rata post-test yaitu 85,20 . Hal tersebut telah dibuktikan dalam pengujian hipotesis, yang menyatakan bahwa hasil sebesar 3,51 sementara dengan db $(n 1+n 2)-2=(15+15)-2=28$ dengan taraf signifikansi 5\% (0.05) sebesar 2,048,. Karena jumlah 3,51>2,048, maka Ho ditolak dan Ha diterima, sehingga hipotesisnya $(\mathrm{Ha})$ berbunyi "ada pengaruh layanan bimbingan kelompok dengan teknik permainan simulasi terhadap kepercayaan diri siswa kelas X MA Futuhiyyah 2 Mranggen".
\end{abstract}

Kata Kunci : Bimbingan Kelompok, Permainan Simulasi, Kepercayaan Diri

\begin{abstract}
This research is motivated by the problems of students 1) do not dare to express opinions in front of the class, feel fear and anxiety in the face of rejection, 2) have not been able to adjust to classmates, 3) there are still students who look down on their own abilities, and can not accept the situation yourself. This study aims to determine whether there is an influence of group guidance services with simulation game techniques on the confidence of class X MA Futuhiyyah 2 Mranggen students. This type of research is quantitative research true experimental design design with pre-test and post-test model control group design. The population in this study was 210 students. Samples in this study were 30 students, taken using cluster random sampling techniques. Can be seen based on the results of the pre-test and post-test. The pre-test average was 73.47 , while the average post-test was 85.20. This has been proven in hypothesis testing, which states that the result of $t$ count is 3.51 while $t_{\text {_ }}$ (table) with $d b(n 1+n 2)-2=(15+15)-2=28$ with a significance level of $5 \%(0.05)$ of 2,048 ,. Because the number of $t$ count> $t$ tabel 3.51>2.048, then Ho is rejected and $\mathrm{Ha}$ is accepted, so the hypothesis (Ha) reads "there is an influence of group guidance services with simulation game techniques on the confidence of class X MA Futuhiyyah 2 Mranggen" students.
\end{abstract}

Keywords : Group of Guidance, Simulation Game Techniques, Self Confidence. 


\section{Pendahuluan}

Pendidikan memiliki peranan penting dalam menciptakan sumber daya manusia yang berkualitas. Pendidikan berfungsi sebagai sebuah proses dimana seseorang dididik agar dapat memiliki kualitas moral dan keahlian yang nantinya akan berguna bagi kemajuan negara ini. Akan tetapi realita di lapangan sistem mutu pendidikan masih tidak efektif khususnya untuk kalangan remaja, dimana mereka memasuki sebuah masa untuk mengenal berbagai macam hal, baik diri mereka sendiri atau hal lain yang berasal dari lingkungan sekitar.

Masa remaja dikenal sebagai masa yang penuh kesukaran. Hal ini disebabkan masa remaja merupakan masa transisi antara masa kanak-kanak dan masa dewasa. Masa transisi ini seringkali menghadapkan individu yang bersangkutan kepada situasi yang membingungkan, disatu pihak remaja masih kanak-kanak, tetapi dalam dilain pihak remaja sudah harus bertingkah laku seperti orang dewasa (Sarlito, 2010, p. 72).

Remaja pada masa kini telah memasuki era generasi millennial, generasi millennial merupakan generasi modern yang aktif bekerja,

mengembangkan penelitian, dan berpikir inovatif tentang organisasi, memiliki rasa optimisme dan kemauan untuk bekerja dengan kompetitif, terbuka, dan fleksibel (Ambarwati \& Raharjo 2018, p. 114). Secara merata generasi millennial mempunyai pendidikan yang lebih baik, cukup terbiasa dengan teknologi bahkan sebagian besar dari siswa sangat ahli dengan teknologi. Dengan kepercayaan diri yang tinggi, generasi millennial mampu bekerja kreatif dan selalu mempunyai energi positif di berbagai bidang.

Kepercayaan diri adalah salah satu kondisi psikologi seseorang yang berpengaruh terhadap aktivitas fisik dan mental dalam proses pembelajaran. Jika dilihat dari segi pendidikan kepercayaan diri sangat menunjang proses pembelajaran di sekolah karena dengan munculnya kepercayaan diri dari dalam diri siswa, segala potensi yang dimiliki oleh siswa dapat berkembang maksimal. Siswa mampu berprestasi baik dalam bidang akademik, non-akademik dan di lingkungan sosial dimana siswa berada (Aunurrahman dalam Sri Marjanti, 2015 p. 2).

Berdasarkan hasil analisis Angket Kebutuhan Peserta Didik (AKPD) yang dilakukan kepada seluruh kelas X MA Futuhiyyah 2 Mranggen menunjukan hasil bahwa kelas X IPA 1 $=3,13 \%$ memiliki permasalahan tidak percaya diri 30 dari 36 siswa, kelas X IPA $2=3,16 \%$ memiliki permasalahan tidak percaya diri 30 dari 39 siswa, kelas X IPA $3=3,24 \%$ memiliki permasalahan tidak percaya diri 30 dari 33 siswa, kelas X IPA $4=3,14 \%$ memiliki permasalahan tidak percaya diri 31 dari 39 siswa, kelas X IPS $1=3,34 \%$ memiliki permasalahan tidak percaya diri 31 dari 33 siswa, kelas X IPS $2=3,17 \%$ memiliki permasalahan tidak percaya diri 28 dari 30 siswa.

Selain hasil analisis AKPD, peneliti melakukan observasi dan wawancara kepada guru BK dan siswa antara lain, 1) masih terdapat siswa yang belum berani untuk mengemukakan pendapat didepan kelas, merasakan takut dan cemas dalam menghadapi penolakan, 2) belum bisa menyesuaikan diri dengan teman kelasnya, 3) masih terdapat siswa yang memandang rendah kemampuan diri sendiri yang mereka miliki, dan belum bisa menerima keadaan diri sendiri.

Menurut (Setiawan dalam Ari Laili Rochmah, 2018, p. 3) orang yang memiliki kepercayaan diri rendah berakibat memiliki perasaan negatif terhadap dirinya dan memiliki kenyakinan lemah terhadap kemampuan dirinya. Maka dari itu pentingnya percaya diri dalam kehidupan siswa menurut Sadeghi (dalam Ari Laili Rochmah, 2018, p. 3) yaitu kepercayaan diri sebagai langkah pertama untuk kemajuan, perkembangan, perbaikan, dan keberhasilan.

Untuk mengembangkan dan meningkatkan kepercayaan diri siswa diperlukan salah satu layanan bimbingan konseling yaitu layanan bimbingan kelompok. layanan bimbingan kelompok merupakan suatu layanan yang memanfaatkan dinamika kelompok untuk membahas berbagai hal yang berguna bagi pengembangan pribadi dan pemecahan masalah yang dialami individu yang menjadi peserta dalam kegiatan kelompok. Selajan dengan pendapat Tumiyem (2018) yang menyatakan layanan bimbingan kelompok adalah suatu kegiatan yang dilakukan oleh sekelompok orang dengan memanfaatkan dinamika 
kelompok Bimbingan kelompok membahas topik umum yang menjadi kepedulian bersama anggota kelompok (Prayitno dalam Eka Wahyu Andani, 2019, p. 12).

Sedangkan menurut (Romlah dalam Ninda Ayu Putri Cahyani 2017, p. 23) permainan simulasi adalah sebuah permainan yang mereflesikan situasi yang terdapat dalam kehidupan nyata dan situasi tersebut selalu dimodifikasikan. Dalam hal ini permainan dalam situasi dimodifikasi dengan tujuan agar tidak terlalu kompleks dan tidak terlalu sederhana.

Adapun tujuan yang ingin dicapai dalam penelitian ini adalah untuk mengetahui pengaruh layanan bimbingan kelompok dengan teknik permainan simulasi terhadap kepercayaan diri siswa kelas X MA Futuhiyyah 2 Mranggen.

\section{Metode}

Metode yang digunakan dalam penelitian ini adalah penelitian kuantitatif dengan pendekatan True Experimental Design. Terdapat dua variabel dalam peneltian ini yakni variabel bebas (layanan Bimbingan Kelompok dengan Teknik Permainan Simulasi) dan variabel terikat (Kepercayaan Diri). Sample penelitian diambil secara random sampling yaitu X IPS 2 yang berjumlah 30 siswa dibagi menjadi kelompok eksperimen dan kelompok kontrol. Desain dalam penelitian ini menggunakan bentuk pretest-posttest control group design.

Tahapan yang dilalui dalam penelitian adalah penyusunan kisi-kisi instrumen, uji coba instrumen, melakukan revisi terhadap instrumen yang belum valid, melakukan pre-test, treatment sebanyak lima kali, dilaksanakan satu kali dalam seminggu dan terakhir post test untuk mengetahui perbedaan sebelum dan setelah diberikan layanan bimbingan kelompok. Instrumen yang digunakan untuk pengumpulan data adalah skala kepercayaan diri yang diberikan langsung kepada siswa yang menjadi subjek penelitian. Uji validitas instrumen menggunakan product moment sedangkan uji reliabilitas menggunakan Alpha Cronbach. Hipotesis yang diajukan dalam penelitian ini adalah layanan bimbingan kelompok berpengaruh atau tidak terhadap kepercayaan diri siswa menggunakan permainan simulasi dikelas X MA Futuhiyyah 2 Mranggen.

\section{Hasil dan Pembahasan}

Setelah diberikan perlakuan melalui bimbingan kelompok selama lima kali pertemuan, kemudian siswa diberikan posttest untuk melihat adakah pengaruh dari bimbingan kelompok terhadap kepercayaan diri siswa dengan teknik permainan simulasi setelah diberikan perlakuan melalui bimbingan kelompok.

Data hasil perhitungan pretest dan posttest menunjukan bahwa dilihat dari total ratarata, telah terjadi perubahan sebelum dan sesudah di berikan treatment berupa bimbingan kelompok dengan permainan simulasi. Untuk memperjelas ada tidaknya pengaruh layanan bimbingan kelompok dengan teknik permainan simulasi untuk kepercayaan diri siswa maka dibawah ini akan dijelaskan dengan tabel

Tabel 1. Distribusi Frekuensi Hasil Pre-Test Kelompok Kontrol dan KelompokEksperimen

\begin{tabular}{|c|c|c|c|c|c|}
\hline \multirow{2}{*}{ Interval } & \multirow[b]{2}{*}{ Kategori } & \multicolumn{2}{|c|}{ Kelompok Kontrol } & \multicolumn{2}{|c|}{ Kelompok Eksperimen } \\
\hline & & $\mathbf{F}$ & $\%$ & $\mathbf{F}$ & $\%$ \\
\hline $91-112$ & Sangat Tinggi & 0 & $0 \%$ & 0 & $0 \%$ \\
\hline $70-90$ & Tinggi & 13 & $87 \%$ & 11 & $73 \%$ \\
\hline $49-69$ & Rendah & 2 & $13 \%$ & 4 & $27 \%$ \\
\hline $28-48$ & Sangat Rendah & 0 & $0 \%$ & 0 & $0 \%$ \\
\hline
\end{tabular}

Berdasarkan hasil pre-test pada kelompok kontrol mengenai skala kepercayaan diri diatas dapat diketahui, 13 siswa pada kategori tinggi presentase $87 \%$ dan 2 siswa pada kategori rendah presentase $13 \%$. Sedangkan hasil pre-test pada kelompok eksperimen 
mengenai skala kepercayaan diri di atas dapat diketahui, 11 siswa pada kategori tinggi dengan presentase $73 \%$, dan 4 siswa pada kategori rendah dengan presentase $27 \%$.

Tabel 2. Distribusi Frekuensi Hasil Post-Test Kelompok Kontrol dan KelompokEksperimen

\begin{tabular}{cccccc}
\hline \multirow{2}{*}{ Interval } & Kategori & \multicolumn{2}{c}{ Kelompok Kontrol } & \multicolumn{2}{c}{ Kelompok Eksperimen } \\
& Sangat Tinggi & 0 & $0 \%$ & F & $\%$ \\
\hline $91-112$ & Tinggi & 15 & $100 \%$ & 7 & $53 \%$ \\
$70-90$ & Rendah & 0 & $0 \%$ & 0 & $47 \%$ \\
$49-69$ & Sangat Rendah & 0 & $0 \%$ & 0 & $0 \%$ \\
$28-48$ & & & & \\
\hline
\end{tabular}

Berdasarkan dari hasil post-test mengalami peningkatan pada kelompok kontrol mengenai skala kepercayaan diri di atas dapat diketahui, 15 siswa pada kategori tinggi presentase $100 \%$. Sedangkan hasil post-test pada kelompok eksperimen mengenai skala kepercayaan diri di atas dapat diketahui, 8 siswa pada kategori sangat tinggi dengan presentase $53 \%$, dan 7 siswa pada kategori tinggi dengan presentase $47 \%$.

Tabel 3. Rekapitulasi Hasil Pretest Posttest Kelompok Kontrol dan Eksperimen

\begin{tabular}{ccccc}
\hline SUBJEK & $\begin{array}{c}\text { PRETEST } \\
\text { EKSPERIMEN }\end{array}$ & $\begin{array}{c}\text { POSTTEST } \\
\text { EKSPERIMEN }\end{array}$ & $\begin{array}{c}\text { PRETEST } \\
\text { KONTROL }\end{array}$ & $\begin{array}{c}\text { POSTTEST } \\
\text { KONTROL }\end{array}$ \\
\hline 1 & 73 & 77 & 78 & 79 \\
2 & 76 & 91 & 75 & 73 \\
3 & 69 & 74 & 73 & 87 \\
4 & 75 & 78 & 75 & 74 \\
5 & 76 & 91 & 68 & 75 \\
6 & 77 & 76 & 78 & 80 \\
7 & 79 & 75 & 78 & 75 \\
8 & 77 & 74 & 70 & 77 \\
9 & 69 & 92 & 73 & 74 \\
10 & 73 & 91 & 81 & 76 \\
11 & 66 & 93 & 69 & 78 \\
12 & 73 & 92 & 70 & 85 \\
13 & 74 & 92 & 76 & 84 \\
14 & 77 & 91 & 76 & 88 \\
15 & 68 & 91 & 74 & 89 \\
JUMLAH & 1102 & 1278 & 1114 & 1194 \\
SEKOR TERTINGGI & 79 & 93 & 81 & 89 \\
SEKOR TERENDAH & 66 & 74 & 68 & 73 \\
RATA-RATA & 73,47 & 85,20 & 74,27 & 79,60 \\
\hline
\end{tabular}

Hasil data tersebut setelah diberikan perlakuan treatment sebanyak lima kali pertemuan berupa layanan bimbingan kelompok dengan teknik permainan simulasi dari hasil posttest pada kelompok eksperimen diperoleh skor rata-rata prettest sebesar 73,47 dan hasil postest sebesar 85,20. Sehingga dapat. Sedangkan pada kelompok kontrol diperoleh skor rata-rata prettest sebesar 74,27 dan hasil postest sebesar 79,60. Sehingga dapat disimpulkan bahwa kelompok kontrol hanya mengalami peningkatan sedikit sebesar 5,33 poin. Hasil dari kedua kelompok tersebut menunjukan bahwa kelompok eksperimen memiliki perbedaan karena diberikan treatment sebanyak lima kali pertemuan sedangkan kelompok kontrol tidak diberikan treatment.

Tabel 4. Uji Hipotesis 
Indonesian Journal Of Educational Research and Review, Vol. 2 No. 3, Oktober 2019 P-ISSN: 2621-4792, E-ISSN: 2621-8984

\begin{tabular}{ccccc}
\hline No & $\mathbf{X}_{\mathbf{1}(\text { exp) }}$ & $\mathbf{X}_{\mathbf{2} \text { (kontrol) }}$ & $\mathbf{X}_{1}{ }^{2}$ & $\mathbf{X}_{2}{ }^{2}$ \\
\hline 1 & 73 & 78 & 5329 & 6084 \\
2 & 76 & 75 & 5776 & 5625 \\
3 & 69 & 73 & 4761 & 5329 \\
4 & 75 & 75 & 5625 & 5625 \\
5 & 76 & 68 & 5776 & 4624 \\
6 & 77 & 78 & 5929 & 6084 \\
7 & 79 & 78 & 6241 & 6084 \\
8 & 77 & 70 & 5929 & 4900 \\
9 & 69 & 73 & 4761 & 5329 \\
10 & 73 & 81 & 5329 & 6561 \\
11 & 66 & 69 & 4356 & 4761 \\
12 & 73 & 70 & 5329 & 4900 \\
13 & 74 & 76 & 5476 & 5776 \\
14 & 77 & 76 & 5929 & 5776 \\
15 & 68 & 74 & 4624 & 5476 \\
$\Sigma$ & 1102 & 1114 & 81170 & 82934 \\
Kode & $\sum X_{1}$ & $\sum X_{2}$ & $\sum X_{1}{ }^{2}$ & $\sum \mathbf{X}^{2}$ \\
\hline
\end{tabular}

Adapun perhitungan untuk uji hipotesis sebagai berikut:

$$
\begin{aligned}
\sum \mathrm{X}_{1}^{2}= & \sum \mathrm{x}_{1}^{2}-\frac{\left(\sum x_{1}\right)^{2}}{N_{1}} \\
= & 81170-\frac{(1102)^{2}}{15} \\
& =81170-\frac{1214404}{15} \\
& =81170-80960 \\
& =210 \\
\sum \mathrm{X}_{2}^{2}= & \sum \mathrm{x}_{2}^{2}-\frac{\left(\sum x_{2}\right)^{2}}{N 2} \\
& =82934-\frac{(1114)^{2}}{15} \\
& =82934-\frac{1240996}{15} \\
= & 82934-82733 \\
\mathrm{X}_{2}=\frac{\sum X 2}{N 2} & =\frac{1114}{15}=74,26 \\
\mathrm{X}_{1}=\frac{\sum X 1}{N_{1}} & =\frac{1102}{15}=73,46 \\
\frac{\sum x}{N} &
\end{aligned}
$$




$$
\begin{aligned}
& t=\frac{\bar{x}_{1}-\bar{x}_{z}}{\sqrt{\frac{\sum x_{2}{ }^{2}+\sum x_{2}^{2}}{N_{1}\left[N_{z}-1\right]}}} \\
& t=\frac{73,46-74,26}{\sqrt{\frac{210+2011}{15[15-1)}}} \\
& t=\frac{-0,8}{\sqrt{\frac{411}{210}}} \\
& t=\frac{-0,8}{\sqrt{1,398}}=\frac{-0,8}{1,182} \\
& t=-0,67
\end{aligned}
$$

Berdasarkan perhitungan uji-t diperoleh hasil $t_{\text {hitung }}$ sebesar $-0,67$ sementara $t_{\text {tabel }}$ dengan $\mathrm{db}=(\mathrm{n} 1+\mathrm{n} 2)-2=(15+15)-2=28$ dan taraf signifikansi $5 \%(0.05)$ sebesar $t_{\text {tabel }}=$ 2,048 , maka $t_{\text {hitung }}<t_{\text {tabel }}-0,67<2,048$. Karena jumlah thitung lebih kecil dari t tabel maka

\begin{tabular}{|c|c|c|c|c|}
\hline No & $\mathbf{X}_{1 \text { (exp) }}$ & $\mathbf{X}_{2 \text { (kontrol) }}$ & $X_{1}^{2}$ & $\mathbf{X}_{2}^{2}$ \\
\hline 1 & 77 & 79 & 5929 & 6241 \\
\hline 2 & 91 & 73 & 8281 & 5329 \\
\hline 3 & 74 & 87 & 5476 & 7569 \\
\hline 4 & 78 & 74 & 6084 & 5476 \\
\hline 5 & 91 & 75 & 8281 & 5625 \\
\hline 6 & 76 & 80 & 5776 & 6400 \\
\hline 7 & 75 & 75 & 5625 & 5625 \\
\hline 8 & 74 & 77 & 5476 & 5929 \\
\hline 9 & 92 & 74 & 8464 & 5476 \\
\hline 10 & 91 & 76 & 8281 & 5776 \\
\hline 11 & 93 & 78 & 8649 & 6084 \\
\hline 12 & 92 & 85 & 8464 & 7225 \\
\hline 13 & 92 & 84 & 8464 & 7056 \\
\hline 14 & 91 & 88 & 8281 & 7744 \\
\hline \multirow{2}{*}{$\begin{array}{l}15 \\
\Sigma\end{array}$} & 91 & 89 & 8281 & 7921 \\
\hline & 1278 & 1194 & 109812 & 95476 \\
\hline Kode & $\sum X_{1}$ & $\sum X_{2}$ & $\sum X_{1}{ }^{2}$ & $\sum X 2^{2}$ \\
\hline
\end{tabular}
Ho diterima. Dapat disimpulkan bahwa "tidak ada pengaruh bimbingan kelompok dengan teknik permainan simulasi terhadap kepercayaan diri siswa kelas X MA Futuhiyyah 2 Mranggen".

Tabel 5. Uji Hipotesis $t$ Test Hasil Post-test

$$
\begin{aligned}
\sum \mathrm{X}_{1}^{2} & =\sum \mathrm{x}_{1}^{2}-\frac{\left(\sum x_{1}\right)^{2}}{N_{1}} \\
& =109812-\frac{(1278)^{2}}{15}
\end{aligned}
$$




$$
\begin{aligned}
& =109812-\frac{1633284}{15} \\
& =109812-108885 \\
& =927 \\
& \sum \mathrm{X}_{2}^{2}=\sum \mathrm{x}_{2}^{2}-\frac{\left(\sum x_{2}\right)^{2}}{N 2} \\
& =95476-\frac{(1194)^{2}}{15} \\
& =95476-\frac{1425636}{15} \\
& =95476-95042 \\
& =434 \\
& \mathrm{X}_{1}=\frac{\sum X 1}{N_{1}}=\frac{1278}{15}=85,2 \\
& \mathrm{X}_{2}=\frac{\sum X 2}{N 2}=\frac{1194}{15}=79,6 \\
& \mathrm{t}=\frac{\bar{x}_{1}-\bar{x}_{2}}{\sqrt{\frac{\Sigma x_{1}^{2}+\Sigma_{x_{2}}^{2}}{N_{1}\left[N_{2}-1\right)}}} \\
& \mathrm{t}=\frac{85,2-79,6}{\sqrt{\frac{227+434}{15[15-1)}}} \\
& t=\frac{5,6}{\sqrt{\frac{1861}{210}}} \\
& \mathrm{t}=\frac{5,6}{\sqrt{2,545}}=\frac{5,6}{1,595} \\
& t=3,51
\end{aligned}
$$

Berdasarkan perhitungan uji-t diperoleh hasil $t_{\text {hitung }}$ sebesar 3,51 sementara $t_{\text {tabel }}$ dengan $\mathrm{db}(\mathrm{n} 1+\mathrm{n} 2)-2=(15+15)-2=28$ dengan taraf signifikansi $5 \%(0.05)$ sebesar 2,048,. Karena jumlah $t_{\text {kitung }}>t_{\text {tabel }} 3,51>2,048$, maka Ho ditolak dan Ha diterima, sehingga hipotesisnya (Ha) berbunyi "ada pengaruh layanan bimbingan kelompok dengan teknik permainan simulasi terhadap kepercayaan diri siswa kelas X MA Futuhiyyah 2 Mranggen".

Berdasarkan hasil hipotesis, layanan bimbingan kelompok efektif untuk meningkatkan kepercayaan diri siswa kelas X MA Futuhiyyah 2 Mranggen. Hal tersebut sesuai dengan pendapat Tohirin (2015, p. 164) yang menjelaskan bahwa layanan bimbingan kelompok merupakan suatu cara memberikan bantuan (bimbingan) kepada individu (siswa) melalui kegiatan kelompok, dalam layanan bimbingan kelompok, aktivitas dan dinamika kelompok harus diwujudkan untuk membahas berbagai hal yang bermanfaat bagi pengembangan atau suatu pemecahan masalah individu (siswa) yang menjadi peserta layanan. Dalam layanan bimbingan kelompok dibahas topik-topik umum yang menjadi kepedulian bersama anggota 
kelompok. Masalah yang menjadi topik pembicaraan dalam layanan bimbingan kelompok, dibahas melalui suasana dinamika kelompok secara intens dan konstruktif, diikuti oleh semua anggota kelompok dibawah bimbingan pemimpin kelompok (pembimbing/konselor).

Lina dan Klara Sr (2010, p. 22), menyebutkan beberapa ciri-ciri individu dengan kepercayaan diri adalah sebagai berikut: 1) Percaya akan kompetensi atau kemampuan diri, sehingga tidak membutuhkan pujian, pengakuan, penerimaan, atau pun rasa hormat orang lain, 2) Tidak terdorong untuk menunjukkan sikap menyesuaikan diri demi diterima orang lain atau kelompok. Remaja seperti ini tidak akan menunjukkan sikap penyesuaian diri supaya diterima oleh sebuah kelompok, 3) Berani menerima dan menghadapi penolakan orang lain, serta berani menjadi diri sendiri, 4) Mempunyai cara pandang yang positif terhadap diri sendiri, orang lain dan situasi di luar dirinya, 5) Memiliki harapan yang realistis terhadap diri sendiri, sehingga ketika harapan itu tidak terwujud, ia tetap mampu melihat sisi positif dirinya dan situasi yang terjadi.

Menurut Tejo Asmara (2018, p. 4) dalam penelitiannya, layanan bimbingan kelompok teknik permainan simulasi dalam meningkatkan kepercayaan diri siswa kelas VIII E di SMP Negeri 3 Suruh Kabupaten Semarang yaitu layanan bimbingan kelompok terbukti efektif dalam meningkatkan kepercayaan diri siswa. Hal ini dapat dilihat dari hasil diterapkan kembali pada siklus 2 terbukti efektif dalam meningkatkan kepercayaan diri dibandingkan siklus 1. Begitupun dengan hasil yang diteliti oleh peneliti di MA Futuhiyyah 2 Mranggen terbukti dapat meningkatkan kepercayaan diri siswa kelas $X$ dengan menggunakan layanan bimbingan kelompok teknik permainan simulasi, hal ini dapat dilihat dari hasil adanya peningkatan skor antara hasil pretest dan posttest setelah pemberian treatment.

\section{Simpulan dan Saran}

Berdasarkan hasil penelitian tentang pengaruh bimbingan kelompok terhadap kepercayaan diri siswa dengan teknik permainan simulasi kelas X MA Futuhiyyah 2 Mranggen dapat disimpulkan bahwa layanan bimbingan kelompok dengan teknik permainan simulasi dapat mempengaruhi kepercayaan diri siswa. Penelitian ini berimplikasi pada pihak terkait, diantaranya yaitu untuk kepala sekolah untuk memberikan pengarahan atau informasi kepada guru BK untuk mengikuti pelatihan agar lebih memahami dan menguasai dalam pemberian layanan bimbingan kelompok. Untuk guru BK yaitu perlu ditingkatkan kemampuan dalam pelaksanaan program bimbingan dan konseling pada layanan bimbingan kelompok..

\section{Daftar Pustaka}

Ambarwati, A., \& Raharjo, S. T. (2018). Prinsip Kepemimpinan Character of A Leader pada Era Generasi Milenial. Philanthropy: Journal of Psychology, 2(2),114.https://doi.org/10.26623/philanthropy.v2i2.115

Ari Laili Rochmah. (2018). Pengaruh Penguatan Positif dan Konsep Diri Terhadap Kepercayaan Diri Sisswa Kelas IV SD Negeri Se-Kecamatan Confidence Of Fourt Grade Students Of State Elementary Schools In. Edisi 36 Tahun Ke 7.

Lina dan Klara Sr. (2010). Pengantar Psikologi Umum. Jakarta.

Rohmah, F. A. (2004). Pengaruh pelatihan harga diri terhadap penyesuaian diri pada remaja. Humanitas : Indonesian Psychologycal Journal, 1(1), 53-63.

Sarlito, S. (2010). Pengantar Psikologi Umum. Jakarta.

Sri Marjanti. (2015). Kata Kunci: Upaya Meningkatkan Rasa Percaya Diri Melalui Konseling Kelompok Bagi Siswa Kelas X IPS 6 SMA 2 Bae Kudus Tahun Pelajaran 2014. 
Tejo Asmara. (2018). Indonesian Journal of Guidance and Counseling. Indonesian Journal of Guidance and Counseling: Theory and Application, 3(3), 38-43. Retrieved from journal.unnes.ac.id/sju/index.php/jbk

Tohirin. (2015). Bimbingan dan Konseling Sekolah dan Madrasah. Jakar.

Tumiyem, Syamsiah. 2018. Pengaruh Layanan Bimbingan Kelompok Terhadap Etika Berkomunikasi Siswa Kelas Xi Ma Pp Daarut Thaalibiin Kota Datar T.P. 2018/2019. JURNAL AL-IRSYAD Vol. VIII, No. 2. 